\title{
Classical Burkitt Lymphoma
}

National Cancer Institute

\section{Source}

National Cancer Institute. Classical Burkitt Lymphoma. NCI Thesaurus. Code C7188.

A Burkitt lymphoma characterized by the presence of a uniform malignant lymphocytic

infiltrate that is composed of medium-sized cells with round nuclei and multiple basophilic

nucleoli, abundant mitotic figures, and a starry-sky pattern due to the presence of

multiple tang ible body macrophages. 